\title{
Study on the Change and Exploration of the Western-style Food Concept of Shanghai Citizens in Modern Times
}

\author{
Xubiao Yang \\ Department of History and Culture, Sichuan University, China
}

Keywords: Modern times, Shanghai, Western-style food, Culture, Communication.

\begin{abstract}
This document explains and demonstrates how the western-style comes in China and how it became the catering fashion among Shanghai people in modern times. It introduces the people's different attitudes to western-style, and the process of acceptance of western-style food. After reading this document you can have a better knowledge of the difference between western-style and Chinese food and the cultural integration.
\end{abstract}

\section{Introduction}

Food and beverage are not only an important part of people's daily necessities, but also a kind of enrichment and refinement of culture. It has a profound influence on the life of the masses. In modern times, China was forced to open its door to be subsumed into the capitalist world system. Since then China and foreign countries have become closer and closer. Many Western goods have been brought in. Thus, with the increasing of foreigners in China, western-style food is also familiar to and accepted by Chinese people.

The introduction of Western-style food has a direct relationship with the economic and cultural communication between China and the west. During the late Ming and early Qing Dynasty, Jesuits brought some eating custom time to time, such as Johann Adam Schall von Bell made "western cakes" to treat Chinese officials in his flat. This kind of cake was made by putting bee, eggs, and flour into two special iron plates. Ludovic Bugli ,Magalhaes, Ferdin and Verbiest wrote the book Yu lan Xifang Yaoji ( Western Record for the Emperor) by excerpting Giulio Aleni's book Xifang Wenda (Answears to the Questions of Western Countries), which briefly introduced the western cooking methods, tableware and diet. Since modern times, foreigners in China increased. They maintained their original western custom. They ate bread, beef and drank milk and coffee. Since they are not accustomed to Chinese food, in order to let them can eat delicious western food in China, some western restaurants came into being in Guangzhou, Shanghai and other trading ports where more foreigners lived in. In 1855, British businessman Holts set up his bakery. In 1858, the Ai Fang foreign Food Firm opened. In 1881, there were 3 bakeries in the French Concession. The flour they used to make bread was all from San Francisco. Wang Tao's book Ying Ruan zazhi mentions that in the north suburb of Shanghai, there were some vegetable gardens that owned by foreigners. There was a kind of vegetable the local people fail to know. Their shapes are just like the oilseed rapes, but differed in their leaf size. Green and crisp, by percolating with boiling water, the flavor is quite good with sauce. Water spinach's stems are very big and the leaves are crisp. It has a good taste with some meat in. From this, we can know that all kinds of vegetables, such as water spinach, salad vegetables, cabbage and asparagus were brought in Shanghai. Western-style food was called "foreign food " "Western food", "dishes "and "dinner". Western-style food restaurants were known as foreign food restaurants in China and first appeared in Guangdong Province. In 1860s and 1870s, with the internationalization of Shanghai, Beijing and Tianjin, foreign food restaurants also appeared in these cities. Initially, the restaurants served the foreigners that lived in China, therefore, the foreign food restaurants were mainly in the foreigners' settlements. In 1880, the most famous restaurant Yi Ping Xiang opened on 
Fuzhou Road. It was the most well-known western-style food restaurant that ran by Chinese businessman in Shanghai in the late Qing Dynasty. It had a good fame because it mainly served for Chinese people and cooked Chinese vegetables with western methods. In the book Life in Shanghai of Sun Yusheng, it says, "There are over 30 rooms in the Yi Ping Xiang Restaurant." Afterwards there were western-style restaurants such as Putian Xiang,Tong Xiang,YiJia Chun,Hai Tian Chun and Tong Ran Chun.Besides, there were Ling Nan Lou,Ping Xiang Chun, San Tai Ge, Putian Chun, Hai Guo Chun, Sihai Chun, Wangnian Chun, Yu Lou Chun and Pu Nan Chun.

When western-style food was introduced into China, in its early time, people in Shanghai were curious about it at the beginning. It's quite understandable because of the food culture difference between China and the west, such as the raw material selection, cooking methods, eating tools, and eating rules. They would confuse when they saw the foreigners using knife and fork but not chopsticks, as well as drinking milk after eat meat at a certain time. Moreover, Shanghai people have smaller appetite, while foreigners eat more. The difference of these prompted people to pay attention to the western-style food in various aspects. Ernest. O Hauser described the Chinese people's views on foreigners in his book Shanghai: City for Sale. It says that the first place that British Consulate General lived in has become the eye-catching place. In the first few days, lots of people, man and woman, old and young, crowed into the flat. They were so curious that they carefully observed them, including their eating, drinking, shaving, washing, reading books, and sleeping.

When people saw all of these, they wanted to try the very different western-style food. Huang Shiquan's book Song Nan Meng Ying Lu (Social Life of Shanghai) recorded the scene that the young people in Shanghai plunged into the restaurants to taste the western-style food."The western-style food is roasted. The meat has smell. Different customs lead to different preferences. Recently there are some foreign restaurants such as Yijia Chun, Yiping Xiang which decorates magnificently and provides good service that almost wins the fame over the restaurants of Suzhou and Tianjin. Food and drinks has tea, snacks and cuisine." Young people are eager to have a taste and take delight in talking about it, while others can't stand it. It is understandable that young people take delight in talking about western food because they are eager to accept new things. However the old are not so easy to accept it. Moreover, there is a lot of half cooked meat in western-style food. Some unique condiments are also unacceptable for most people, such as curry. Most Chinese people, including young people, cannot accept the flavor of western-style food in a short term. American William C. Hunter in his book Miscellanies in Old China wrote that in a letter of the son of a businessman whose last name is Luo, he described the scene of westerners' catering with a satire voice: They sit by the table to eat a kind of liquid, which is called soup. Then they masticated the fish rudely. The fish was almost as raw as live fish. Afterwards, there were plates of half cooked meat on every corner of the dining table. All the meat was soaked in the juice. You must use a knife to cut it into pieces to serve it to the guests. I saw all of these so I can confirm what I hear from others before: The foreigners have bad temper because they eat these coarse raw food....The meat beaten by people is thrown to dogs. The dogs were allowed to walk under people's laps and lie under the dining table. They kept humming and fighting. Then another awful spicy food was served. Someone near my side called it curry by English. As for me, the rice was the only food I can accept. After that a kind of green and white food with a strong odor was carried on the table. They told me it was a mixture with sour water and milk. They put it under the sun till it grew insects. The color is greener, and the smell is stronger. It is cheese. They ate it with the red liquid. This kind of liquid has bubbles that will spill out of the cup to dirty the clothes. They call it beer. The son of the business is young. From this material, we can know that at that time young people failed to accept the western food quickly. That's why he used the satire voice to describe it and used the words coarse and raw to modify the western-style food. Even though the beer, this young man said it with derogatory sense because it would make the clothes dirty. And obviously he cannot eat the main condiment in western-style food---curry. In his eyes, it's rude to masticate the raw fish and meat. Besides, Chinese people doesn't keep dogs like westerners, because they always tie dogs in a certain place and pour the leftovers into the bowl before it to raise it. The scene of eating and raising dogs of westerners seem not so beautiful. Chinese people will has the same feeling on the western-style food as the young man, for example when Zhang Deyi first was sent as an envoy to 
Europe, he ate the western-style food first time. He felt bad. In his later book Wonders during the Voyage, he wrote, "On the ocean-going vessel, there was a rule that meals were after the bell. Afterwards every time when I heard the bell ring, I spit. That's because the western-style food and drinks are different from those of China's. The food is not what they eat usually, so it is hard to accept. And the food has all flavors, sour, sweet, bitter and hot. The meat is cut into huge pieces. Some is ripe and burnt, while some is raw and hard. The meat is roasted but not cooked. The fish and shrimp are so hot and sour that it is hard to smell." All of the materials show that Zhang Deyi firstly failed to accept the unique taste of western-style food. Even if some Chinese people tasted it because of curiosity, the mainstream of society still held the exclusion mentality towards western-style food.

With the increasingly frequent communication between China and the west, Chinese people had known more about the west, and the understanding of Western food had also changed. In the 1970s, there had been records about Chinese people eating western-style food. In the diary of the famous scholar Sun Baoxuan in Shanghai, after comparing the difference between Chinese and western food, he wrote," The westerners have a coarse diet. They usually give priority to the health which is as the same as the concept of diet therapy in the book Rites of Zhou. Westerners eat food with the big plates. On the plates there are beef, mutton, fish and duck meat and taro and beans are put near the meat. Rites of Zhou says, "beef should be eaten with Tu rice, mutton with Su rice, pork with Ji rice, dog meat with Liang rice, the wild goose with wheat and fish with Gu rice. I think that the old Chinese people keep a healthy diet the same as the westerners in some way."The book also says, "the temperature of food should be like the climate of spring. The soup should be like the summer. The sauce should be like the autumn. And the drinks should be like the winner. That is, the food should be warm; the soup should be hot; the sauce should be cool and the drinks should be cold. Chinese people mostly drink warm alcohol recently. While the westerners like drinking cold beer and cold water, which is quite the same as the book says." In May 1878, when Wang Tingding, the student of Yu Yue , stayed in Shanghai, Mo Xiangzhi, Shanghai county magistrate, invited him to enjoy the "Yi cuisine", that is western-style food in Xu Yuan Park. The behavior of the county magistrate stands for the local customs. It is a simple individual behavior. But it also shows us the recognition of Western-style food in Shanghai has reached a higher level to some extent. By 1890s, the western-style food restaurants where few people liked to go before had become the boisterous places. In 1909, Shanghai's scholar Zhu Wenbing made a poem named Haishang Zhuzhi ci, he wrote it was quite popular to treat people with the western-style food in Shanghai. Everybody should sit a bit far from others. The hosts were so hospitable to teach us to order. The scene of the catering was so bustling, extravagant. All of these showed that people paid more attentions to the western-style food. With the xenophilia psychology, eating western-style food had become a byword for opening the horizon and catching up with the fashion. There were two things that People from other cities had to do when they visited Shanghai. One was eating western-style food, another was riding the carriage. Cuisine is western food, also called foreign food in Shanghai. I don't know why people call it "cuisine". Eating in the western-style food restaurants had become an honor for the middle and upper classes. In Beijing, some government officials even changed their traditional eating custom. "They ate western-style food with the western tableware. They treated others almost in the Chinese restaurant Tong Feng Tang ,Hui Xian Tang before. But now they treat them in the western-style food restaurants, such as Liu Guo Restaurant, De Chang Restaurant, Cang'an Restaurant."'Once they drank the Shaoxing wine, while now they drink brandy and beer."During the period of the Republic of China, Shanghai had more restaurants. On the Nanjing Road, there had Qi Chongtian, Da Dong,Dong Ya, Xinxin, Xindu, Sullivan, Jimei, Maershi, Yili.On the Tibet Road, there is Gold valley, jazz ,Da Zhonghua. On the Fuzhou road, there is the Atlantic, central, Indian Curry restaurant. On the Jingan Temple road, there is International Hotel, Kinmen, West YMCA, Xinsha Hua, Feida, DA Lai, and Lai Xi. However Xia Fei Road had the most. It was said that even the Russian restaurants there are 20-30.So many Western-style restaurants marked the preference of Western-style food in Shanghai.

While people are paying more attention to Western food, we should also see that food and beverage as a kind of culture are enriched with cultural marks of their respective nationalities. After 
the introduction of western food, not only its materials, cooking methods but also the eating patterns embody the fusion and conflicts between Chinese and western dietary culture. People in the late Qing Dynasty had also made some explorations and tried their best to achieve the goal of combining the Chinese food and western-style food. For example, Sarah Conger, the wife of the U.S. ambassador accredited to China, wrote to her sister on August 15, 1898. In the letter, she said "when we came to the Shanghai concession, Shanghai Daotai (the local officer) officially visited us. He held a banquet for us later. At the banquet, the dishes were half foreign dishes and half Chinese dishes, which were alternately served. Chinese food was served in the Chinese dishes and eaten with chopsticks, and foreign food was arranged strictly according to western tradition. Daotai spoke English very well. So did his sectary who studied in the U.S. They delivered the welcome words respectively. "During the reception of the U.S. ambassador to China, Daotai not only respected westerners' dining habits, but also displayed the Chinese food and dining culture in a perfect way. In addition, the Chinese people's exploration of Chinese and western food also included the reformation of western-style food, which catered for the taste of Chinese people. This formed the so-called "Chinese cuisine", such as "grilled beef", "ridge cooked in Chinese and western style ","prawns cooked in western style "'duck livers cooked in western style " and so on. After the transformation of western-style food, it gradually formed the western-style food with various Chinese local characteristics, such as Canton cuisine, Ningbo cuisine, Shanghai cuisine, etc. Among them, the cooking method of Ningbo cuisine meets the taste of Shanghai people most, because Shanghai people like to eat seafood and salty food, and the taste of Ningbo cuisine is tender and smooth, fresh and salty, thus Ningbo cuisine is favored by many Shanghai people. The changed western-style food became more and more popular at that time, Cao Juren said,"having a big meal at Yipinxiang Restaurant, in fact, is eating Chinese food in western way. Only in this way, can Chinese people feel free to eat food in here. For example, the steak is not so bloody, otherwise, it would look scary. " This shows that eating Chinese food in western way created by Chinese people is successful. Shanghai Leiqian Western Restaurant is famous for its Shanghai western food ,which is created by combining the characteristics of Chinese food and western food. This shows that after western-style food was introduced into China, some western restaurants, in order to make more profit, also made some changes to western food to cater for the tastes of Chinese people. These are good examples to witness the culture combination of Chinese food and Western-style food.

After comparing with the Chinese food and western-style food, the men of insight found that the western-style food is cleaner to some extent. Chi Zhicheng's book Tour in Shanghai wrote "the foreign restaurants are the big dining rooms. The buildings and tableware imitate the western style, quite exquisite and clean. The restaurants on Sima Road, such as Haitian Chun, Yijia Chun, Yiping Chun and Xinglin chun are all like this. Everybody has his own dishes in different plates. Never share with others. One table has one or two people, or more than ten people. The fee is calculated according to the number of customers regardless of the number of people. Food and drinks are tea, snacks, cuisines and the well-know Chinese and foreign wines." "Everybody has his own dishes in different plates." that is the western individual dining system. This diet is simple, hygienic and socially appropriate, so since the late Qing Dynasty, nutritionists have called for a separate meal system for health and hygiene. Since the middle of 19th Century, due to the influence of western culture, there was a fashion to change the style of banquet in Chinese scholars' circle. According to Chinese and Western banquet specifications, they created the Chinese and Western banquet. American minister Mrs. Conger described their lunch that his servants prepared for them: "when it's time for dinner, 12 home cooking dishes were prepared on the table in a big room. There were pickles, sweets and flowers on the table, all of which were the servants prepared." At the same time, there were also wash basins, water tanks and towels, ice cubes and distilled water. Mrs. Conger friends cheered: "Great! Great!" This is the example of the combination of Chinese and Western-style food. In 1887, Hong Jun, who was sent to Germany, treated the European people with Chinese food. The chef was especially asked to make the dishes lighter and less greasy. That's because greasy is one of the major drawbacks of Chinese food. The method of eating is to eat separately. Cai Yuanpei explained more clearly in his 
book Thirty-five years of New Culture in China. It says,"The Chinese food have some shortcomings: Firstly, some people prefer the flavor; while some just want to be full. The distribution of protein, sugar, fat, and the need of vitamin are not to be considered. Secondly, when having dinner at home, they share the chopsticks, spoon, and there is a risk of infectious diseases. In recent years, with the influence of Europeanization, Western-style food had become more popular. People realized that Chinese food is actually better than western-style food. The methods of cooking just needed be improved. So some people eat Chinese food with the methods of western-style food or put the special spoon and chopsticks to fetch the dishes when they have the Chinese food. It can prevent infection, and all kinds of ingredients are easy to be distributed." In the process of constructing the modern multicultural city of Shanghai, various factors of western-style, including western-style food and western-style food restaurant, knowledge of western-style and health system, the dining etiquette, have become an important component of the urban culture of modern Shanghai.

\section{References}

[1] Yao Weijun, Evolution of Dietary Life and Social Transition, Exploration and Contention, vol. 4,1996.

[2] Wang Tao,Ying Ruan Zazhi, p.18.

[3] Sun Yusheng,Life in Shanghai, Qin Ji Le Qun Publishing House,p.18, 1915.

[4] Guide to Shanghai,The Commercial Press,Ltd,Shanghai, 1909.

[5] Ernest. O Hauser, translated by Yue Yi, Shanghai: City for Sale, Da Di Press, pp. 7-9, 1941.

[6] Huang Shiquan,Song Nan Meng Ying Lu (Social Life of Shanghai), Shanghai Classic Press, p.132, 1989.

[7] William C. Hunter, translated by Shen Zhengbang,edited by Zhang Wenqin, Miscellanies in Old China, Guangdong People's Publishing House, pp. 41-43, 2001.

[8] Zhang Deyi, Wonders during the Voyage, Yue Lu Press, pp. 449-450, 1985.

[9] Sun Baoxuan, Diary of Forgotten Mountain Cottage, Shanghai Classic Pres , p. 81, 1895.

[10] Wang Tingding, Diary Written in Crape Myrtle Garden, selected from Diaries in Qing Dynasty, Shanghai People's Press, p. 326, 1982.

[11] Zhu Wenbing, Zhuzhi Ci, Shanghai bookstore Publishing House, pp. 190-191,1996.

[12] Bao Xiaotian, Memoirs of Bracelet Shadow Chamber, Da Hua Press,p. 31, 1971.

[13] Hu Pu'an,The Chinese national Custom, Shanghai Da Da Bookstore Supply Agency, vol.1,1936.

[14] Sarach Pike Conger, Letters from China, translated by Shen Chunlei, Nanjing Press, p. 3,2006.

[15] Chi Zhicheng, Tour in Shanghai, Shanghai Classic Press, p. 158,1989..

[16] Liu Bannong, Sai Jinhua, Yue Lu Press, p.12, 1985.

[17] The Collected Works of Cai Yuanpei(6), Zhonghua Book Company, P74, 1988. 